\title{
Radon in the dry carbon dioxide spa of Mátraderecske, Hungary
}

Erzsébet Sóki, István Csige

\begin{abstract}
The final product of a post-volcanic activity is the exhalation of low-temperature $\left(<100^{\circ} \mathrm{C}\right)$ gases containing mostly carbon dioxide. The phenomenon is called mofettes, which are often used for therapeutic treatments in the form of dry $\mathrm{CO}_{2}$ spas. Along its pathway to the surface, the deep origin gas also intakes different radon isotopes from the rocks and soils; therefore, the risks associated with radon exposures should also be a concern. In this work, we have found that the ${ }^{222} \mathrm{Rn}$ activity concentration in the mofette gas of Mátraderecske is particularly high; it is in the order of $200 \mathrm{kBq} \cdot \mathrm{m}^{-3}$. However, owing to the carefully designed flow pattern of mofette gas and fresh air, the radon level is about $1 \mathrm{kBq} \cdot \mathrm{m}^{-3}$ at the breath level of the staff, accompanying the treatment, which is the radon reference level for workers in Hungary. We have also found that in this dry spa, radon is a good tracer of $\mathrm{CO}_{2}$; therefore, it can be used to monitor the $\mathrm{CO}_{2}$ distribution in the treatment pools.
\end{abstract}

Key words: dry $\mathrm{CO}_{2}$ spa $\bullet$ mofette $\bullet$ radon $\bullet$ tracer

\section{E. Sóki ${ }^{\bowtie}$}

Department of Environmental Physics, University of Debrecen - MTA Atomki, Poroszlay u. 6, H-4026 Debrecen, Hungary, Tel.: +36 52509 296, Fax: +3652 416 181, E-mail: soki.erzsebet@atomki.mta.hu

I. Csige

MTA Atomki,

H-4001 Debrecen, P. O. Box 51, Hungary

Received: 15 January 2016

Accepted: 21 March 2016

\section{Introduction}

The final product of a post-volcanic activity is the exhalation of a low-temperature $\left(<100^{\circ} \mathrm{C}\right)$ deep origin mofette gas, which contains mostly carbon dioxide. Examples of mofettes are the Torjai-Büdös cave in Transylvania, Romania [1] or the $\mathrm{CO}_{2}$ seepage in Mátraderecske, Hungary [2]. The term 'mofette' derives from the Latin word 'mephitis,' which means smelly exhalation [3]. Along its path to the surface, the deep origin gas also intakes different radon isotopes from the rocks and soils. Therefore, the variation of surface radon exhalation can be a tracer of spots of $\mathrm{CO}_{2}$ outgassing.

Mofettes are often used for therapeutic treatments in the form of dry $\mathrm{CO}_{2}$ spas, where the risks associated with radon exposures should also be a concern. Carbon dioxide bath has a several-century tradition in countries where gas discharges were found, even the ancient Romans knew this treatment. The curative gas is applicable for treating cardiac and peripheral artery diseases (arteriosclerosis in the lower limbs, coronary diseases), high blood pressure, arterial complications in diabetics, postoperative treatment following arterial surgeries. The human body reacts to the absorbed gas in a way that the blood vessels in the skin become dilated, the capillary circulation is intensified, the speed of blood flow is increased (e.g. the circulatory performance is increased) and the oxygen supply provided to the 
organs is also enhanced. The contraindications of the therapy are the same as for any other spa visit. Patients with heart failure, hypertension, asthma, tumours, inflammatory diseases or conditions with frequent loss of consciousness are not allowed to use the mofette. Pregnancy and menstruation also disqualify $[4,5]$.

The aim of this work was the study of spatial and temporal variation of radon in the mofette of Mátraderecske, Hungary, and the analyses of the results in environmental physical, geochemical and environmental radiation protection points of view. The dry carbon dioxide spa of Mátraderecske is used for therapeutic treatments. High radon levels were observed; therefore, radon exposure and effective dose for patients and staff were also determined.

\section{Material and methods}

\section{Study area}

Mátraderecske is situated at the foot of the Mátra Mountains, which is one of the largest units of the calc-alkaline Inner Carpathian volcanic arch, additionally the largest tertiary volcanic range of Hungary [6].

The elevated radon exhalation in Mátraderecske is geologically extraordinary, since the uranium concentration of andesite is merely $3 \mathrm{ppm}$, while the thorium content does not exceed $40 \mathrm{ppm}$. Two hypotheses can explain this phenomenon: (1) Along its path to the surface, the deep origin gas intakes different radon isotopes from the andesite and accumulates under the insulating clay layer. Where the clay layer is thin enough or absent, radon can diffuse. (2) The origin of radon can be a secondary enhancement of the soluble decay products of uranium, accumulated in the clay layer [7].

The dry carbon dioxide spa of Mátraderecske (briefly Mofetta) has two dry $\mathrm{CO}_{2}$ pools that are located on the east end of the building complex. The pool on the north side is called Pool I, while the other on the south side is called Pool II. The $\mathrm{CO}_{2}$ gas is coming up from the bottom of the pool and fills it up to a height of approximately $1.1 \mathrm{~m}$. During treatment, the patients are sitting in the pool and are partially immersed in the curative gas for nearly half an hour.

\section{Radon measuring methods}

We have measured the spatial distribution of the ${ }^{222} \mathrm{Rn}$ activity concentration in the pool of the mofette with Radamon type etched track radon detector containing poly allyl diglycol carbonate (PADC) nuclear track detector (known with its trade name CR-39: Columbia resin 1939) [8]. The Radamon was calibrated at the Health Protection Agency, Radiation Protection Division of the UK. We have also used an ionization chamber-based AlphaGUARD-PQ2000 type [9], and two semiconductor detectors-based Dataqua type [10] continuous ${ }^{222} \mathrm{Rn}$-monitors to measure the temporal variation of the ${ }^{222} \mathrm{Rn}$ activity concentration in the air above the pool. These instruments also recorded the temperature, atmospheric pressure, and relative humidity. We have also used a Weather Monitor II type micro-meteorological station (Davis Instruments Corp. Hayward, California, United States). This station is an automatic weather station, which can be used to measure practically all weather parameters we thought to be relevant for radon transport in soils.

\section{Personal radon dosimetry}

In order to determine the radon exposure and to estimate effective dose of individual spa workers, each of them had to wear a personal radon dosimeter during working hours for over a whole year. For this purpose, we have used the small volume $\left(7 \mathrm{~cm}^{3}\right)$ etched track type radon monitors (called Radamon). During working hours (48 h/week), the crew (5 people) had to wear the dosimeters as a necklace (the closer to the mouth), otherwise these were stored in a key box that contained an extra dosimeter used for background measurements. After exposure, the CR-39 track detectors were etched in a $6.25 \mathrm{~N} \mathrm{NaOH}$ solution at $70^{\circ} \mathrm{C}$ for $5 \mathrm{~h}$. The track density was counted under an optical microscope manually. The scanned area was $1 \mathrm{~cm}^{2}$ for low track densities. At higher track densities, a total of around 1000 tracks were counted.

The track density $(\rho)$ is directly proportional to radon exposure $\left(E_{\mathrm{Rn}}\right)$, that is, to the product of the average radon activity concentration $\left(\bar{C}_{\mathrm{Rn}}\right)$ and exposure time $\left(T_{\exp }\right)$. The proportional constant is the sensitivity of the radon detector to radon exposure, which is the inverse of the calibration factor.

However, the radon dosimeters collected the tracks both during the time that they were worn as personal dosimeter (48/168-th part of the total time) and during the time that they were stored together with the background detector in the key box (120/168-th part of the total exposure time). Assuming that the radon activity concentration in the key box was constant, we need to subtract the 120/168-th part of the radon exposure of the background detector from the measured radon exposures of the radon dosimeters to obtain the radon exposures of the staff members.

The equilibrium factor $F$, is defined as the ratio of the equilibrium-equivalent decay product activity concentration to the radon activity concentration. We used the value of $F=0.4$. The formula for potential alpha-energy exposure is:

$$
P_{p}=5.56 \times 10^{-6} \cdot F \cdot E_{\mathrm{Rn}}
$$

where: $P_{p}$ represents the potential alpha-energy exposure $\left[\mathrm{mJ} \cdot \mathrm{m}^{-3} \cdot \mathrm{h}\right] ; E_{\mathrm{Rn}}$ is the measured radon exposure $\left[\mathrm{Bq} \cdot \mathrm{m}^{-3} \cdot \mathrm{h}\right]$.

In order to be able to compare the radon exposure with the quantities generally used for dose limitation in radiation protection, we converted the radon exposures into effective doses. For this, we used 
Table 1. Effective doses of staff from inhalation of the ${ }^{222} \mathrm{Rn}$ decay products

\begin{tabular}{lccccc}
\hline $\begin{array}{c}\text { Code number } \\
\text { of workers }\end{array}$ & Sex & $\begin{array}{c}\bar{C}_{\mathrm{Rn}} \\
{\left[\mathrm{Bq} \cdot \mathrm{m}^{-3}\right]}\end{array}$ & $\begin{array}{c}E_{\mathrm{Rn}} \\
{\left[\mathrm{MBq} \cdot \mathrm{m}^{-3} \cdot \mathrm{h}\right]}\end{array}$ & $\begin{array}{c}P_{p} \\
{\left[\mathrm{~mJ} \cdot \mathrm{m}^{-3} \cdot \mathrm{h}\right]}\end{array}$ & $\begin{array}{c}E \\
{[\mathrm{mSv}]}\end{array}$ \\
\hline 1 & $\mathrm{M}$ & $463 \pm 23$ & 1.99 & 4.43 & $6.3 \pm 0.6$ \\
2 & $\mathrm{M}$ & $293 \pm 13$ & 0.66 & 1.47 & $2.1 \pm 0.4$ \\
3 & $\mathrm{~F}$ & $598 \pm 28$ & 3.05 & 6.78 & $9.7 \pm 0.7 *$ \\
4 & $\mathrm{~F}$ & $299 \pm 13$ & 0.71 & 1.58 & $2.3 \pm 0.4$ \\
5 & $\mathrm{~F}$ & $317 \pm 14$ & 0.85 & 1.89 & $2.7 \pm 0.4$ \\
\hline
\end{tabular}

*Worker-3, by her own admission, often left her dosimeter in the medical room hanging on the filing cabinet.

the conversion factor recommended by ICRP-65. According to this, $1 \mathrm{~mJ} \cdot \mathrm{m}^{-3} \cdot \mathrm{h}$ of potential alpha-energy exposure corresponds to $1.43 \mathrm{mSv}$ effective dose for workers.

We have defined the lower limit of detection (LoD) as the effective dose for which the relative uncertainty is $50 \%$, that is, $\mathrm{LoD}=2 \sigma_{\mathrm{LoD}}$. $\sigma_{E}$ was calculated using the Gaussian error propagation formulae.

Dose estimation is affected by not just random errors of radon measurements, but systematic errors too, which can be even a factor of $2-3$. The radiation exposures received by the spa workers from radon in 2006 are summarized in Table 1 . In previous years, the ${ }^{222} \mathrm{Rn}$ activity concentration was around $600 \mathrm{~Bq} \cdot \mathrm{m}^{-3}$ in the medical room. This value is absolutely identical to the average radon activity concentration $598 \pm 28 \mathrm{~Bq} \cdot \mathrm{m}^{-3}$ shown by Worker-3's dosimeter in the current period. On that basis, we assume that the dosimeter was most of the time in the medical room; thus, it is not suitable for estimating personal radon exposure. A better estimation can be obtained if we take into account the average Rn activity concentration measured in the medical room and 2000 working hours per year as a starting point. According to this, the radiation exposure received by Worker-3 from radon in 2006 (expressed in effective dose) is $E=3.9 \mathrm{mSv}$. It is also needed to be considered that the doors and windows of the medical room were kept closed at night, while during the working hours, those were opened all the time. Hence, the radiation exposure estimated from the average ${ }^{222} \mathrm{Rn}$ activity concentration can be regarded as an upper limit.

Exposure of patients to radon were also considered. The exposure time of patients for a whole cure is about $7 \mathrm{~h}$. The radon activity concentration at the mouth level of the patients is in the order of $10 \mathrm{kBq} \cdot \mathrm{m}^{-3}$. The corresponding effective dose for patients is in the order of $0.2 \mathrm{mSv}$ for a cure.

\section{Radon activity concentration in the mofette}

In 2013, we measured the average Rn activity concentration in the air of the dry $\mathrm{CO}_{2}$ pools of the dry carbon dioxide spa of Mátraderecske (Figs. 1a and 1b) with Radamon type etched track radon detectors. The measurement points were selected in such a way to get information from the source of radon gas and the spread of it around the pools.

We have found that the ${ }^{222} \mathrm{Rn}$ activity concentration in (northern) Pool I is particularly high; at
$-1.1 \mathrm{~m}$, it is about $200 \mathrm{kBq} \cdot \mathrm{m}^{-3}$. However, it decreases with the distance from the bottom of the pool. It is approximately $10 \mathrm{kBq} \cdot \mathrm{m}^{-3}$ at the edges of the pool. This phenomenon can be explained by the mixing of medicinal gas with the ambient air.

The somewhat lower radon activity concentration $\left(150 \mathrm{kBq} \cdot \mathrm{m}^{-3}\right)$ in (southern) Pool II derives from the lower gas flow rate into this pool. Furthermore, the $\mathrm{CO}_{2}$ concentration is also smaller, which indicates that the mixing process has already occurred at the bottom of the pool.

By establishing a carefully designed air flow ventilation pattern (Fig. 2) using suction of gases in the middle of the pools, we were able to achieve high $(60-80 \%) \mathrm{CO}_{2}$ concentration at the lower limbs while maintaining a low concentration of both radon (a few $\mathrm{kBq} \cdot \mathrm{m}^{-3}$ ) and $\mathrm{CO}_{2}(4-5 \%)$ at the mouth level of the patients sitting in the pool.

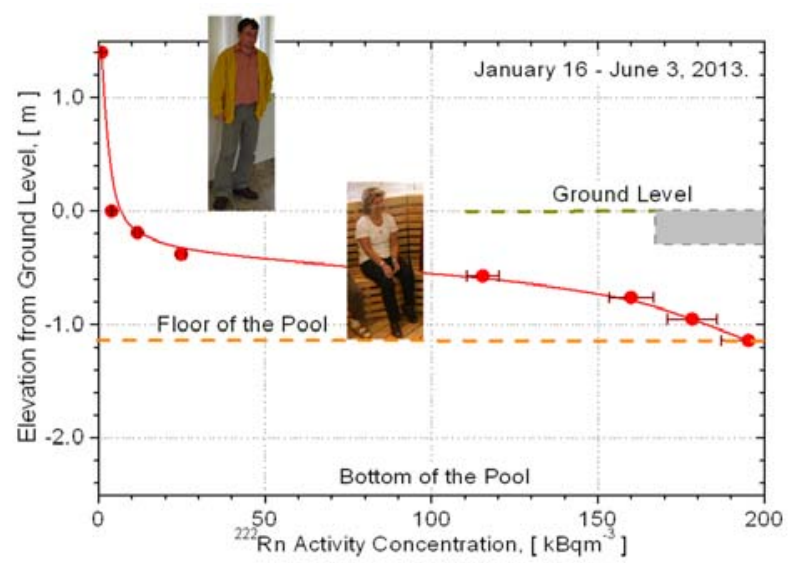

Fig. 1a. The vertical profile of the ${ }^{222} \mathrm{Rn}$ activity concentration in the airspace of Pool I.

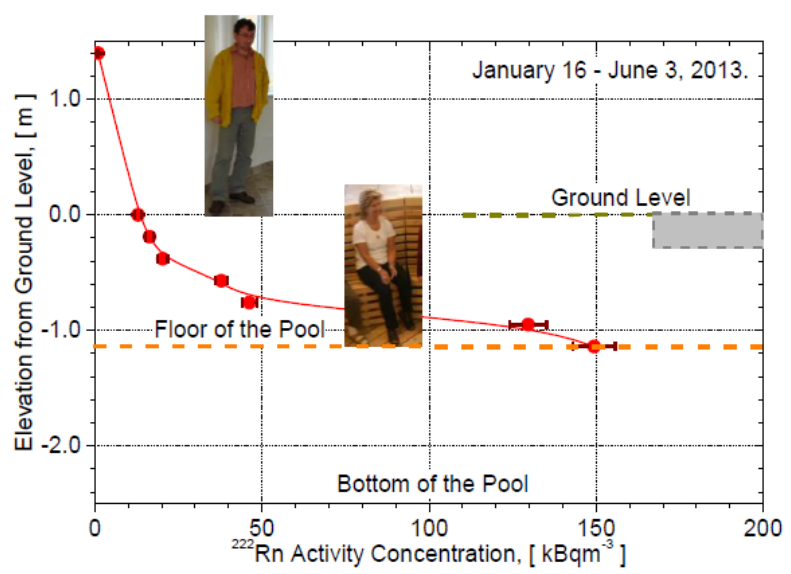

Fig. 1b. The ${ }^{222} \mathrm{Rn}$ activity concentration in Pool II as a function of elevation from the ground level. 


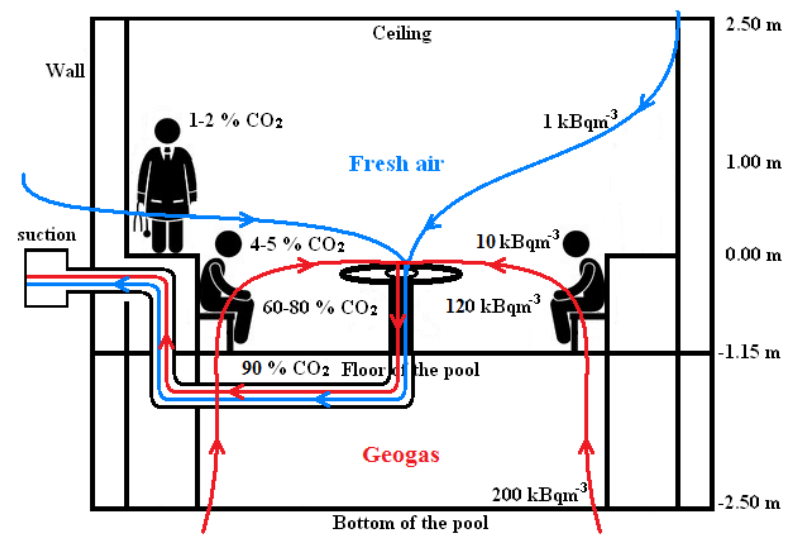

Fig. 2. Schematic for geogas and fresh air flow pattern in the spa of Mátraderecske.

\section{Correlation of radon emanation with the meteorologi- cal parameters}

The radon activity concentration is greatly influenced by the meteorological parameters. For that reason, simultaneously with activity concentration measurements, we monitored the temperature of air, relative humidity, and pressure. In Pool II we used two semiconductor detectors-based Dataqua type continuous ${ }^{222} \mathrm{Rn}$-monitors for this purpose. One of the instruments was placed at the ground level $(0.0 \mathrm{~m})$, at the edge of the pool, horizontally. The other one was put at the bottom of the pool $(-2.5 \mathrm{~m})$ on the south-western part of it at the staircase railing. These devices were also calibrated at the Health Protection Agency, Radiation Protection Division of the UK.

The measuring data shows (Figs. 3 and 4) that the ${ }^{222} \mathrm{Rn}$ activity concentration at the bottom of the pool $(-2.5 \mathrm{~m})$ is a stable high value and there was no significant change over time. Contrary to the ground level $(0.0 \mathrm{~m})$, a characteristic daily change was observed with a day-time minimum and night-time maximum. In the analysed period, the doors and windows of the room were kept closed all the time. The suction fan in the middle of the pool was operated continuously (from 6 a.m. to 4 p.m.). As a result, a significant decrease occurred in the day-time ${ }^{222} \mathrm{Rn}$ activity concentration levels $\left(2-5 \mathrm{kBq} \cdot \mathrm{m}^{-3}\right)$

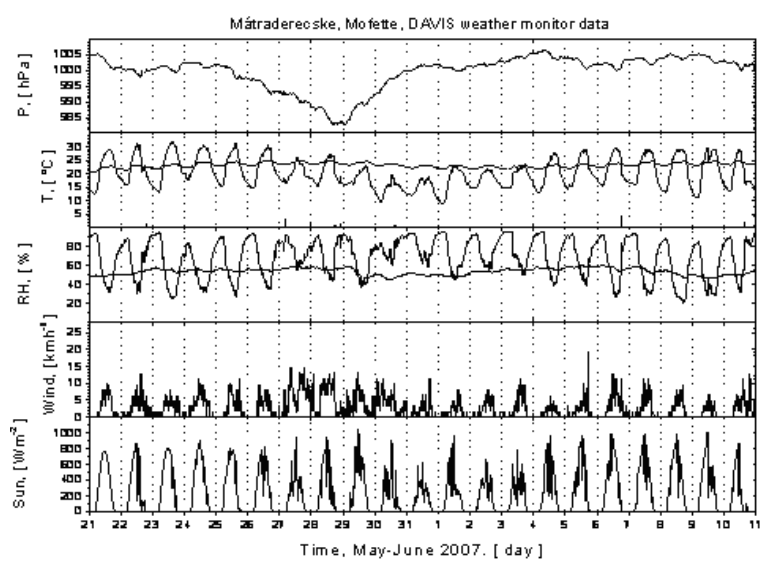

Fig. 3. Temporal variation of the parameters recorded by Davis weather monitor.

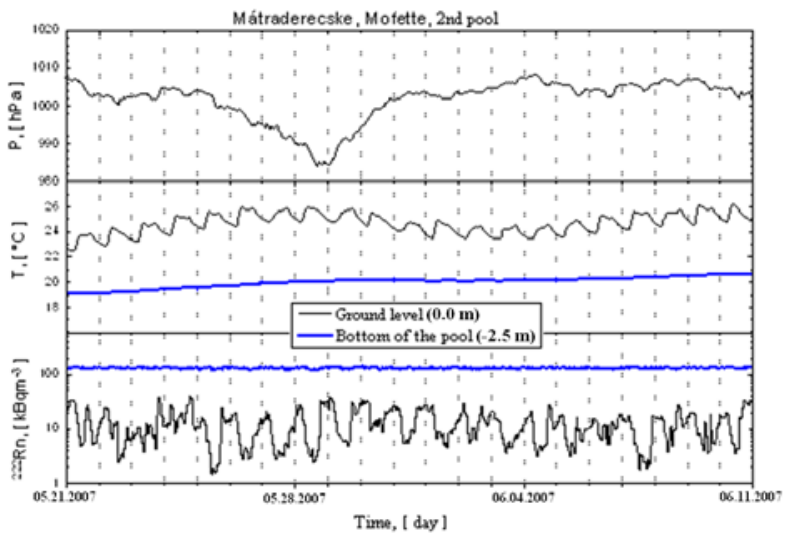

Fig. 4. Temporal variation of pressure, temperature, and ${ }^{222} \mathrm{Rn}$ activity concentration in Pool II at the ground level and at the bottom of pool.

compared with the typical night-time values $\left(20-30 \mathrm{kBq} \cdot \mathrm{m}^{-3}\right)$.

\section{Conclusion}

Our measurements prove that the origin of ${ }^{222} \mathrm{Rn}$ is the curative $\mathrm{CO}_{2}$ seepage from the bottom of the pool. We have observed that radon is transported by the carrier gas. The ${ }^{222} \mathrm{Rn}$ activity concentrations at the bottom of the pools are between $150-190 \mathrm{kBq} \cdot \mathrm{m}^{-3}$. A higher radon activity concentration is found in Pool I, which is related to the fact that the gas flow is higher than in Pool II. Additionally, the concentration of $\mathrm{CO}_{2}$ is more than $90 \%$ at the bottom of Pool I, in contrast to Pool II. The concentration of $\mathrm{CO}_{2}$ is lower too, which indicates that the mixing of curative gas with the ambient air in Pool II takes place already at the bottom. This is indicated by the measured radon activity concentrations, too. The ${ }^{222} \mathrm{Rn}$ activity concentration decreases with the distance from the bottom of the pools to such an extent that at the edges of the pool, it is approximately $10 \mathrm{kBq} \cdot \mathrm{m}^{-3}$. There is a considerable difference between the two pools. While at Pool I the radon concentration under the waist level is high and above it decreases rapidly, at Pool II the transition is not so sharp.

From the comparison of radon and $\mathrm{CO}_{2}$ concentrations, we have found that in this dry pool, radon is a good tracer of the $\mathrm{CO}_{2}$ concentration, too. The transport is influenced by the meteorological parameters. The radon concentration at the ground level varied proportionally with temperature and inversely with pressure, while at the bottom of the pool, the radon values were stable.

The ${ }^{222} \mathrm{Rn}$ activity concentration at the breath level of the staff, accompanying the treatment, is in the order of $1 \mathrm{kBq} \cdot \mathrm{m}^{-3}$, which is the radon reference level for workers in Hungary.

\section{References}

1. Szabó, Á. (2005). Radioaktív ásványvizek és mofettagázok. Cluj-Napoca: Stúdium Könyvkiadó. 
2. Vásárhelyi, A., Hunyadi, I., Csige, I., Hakl, J., Hertelendi, E., Borossay, J., \& Torkos, K. (1997). Radon enriched deep earth-gas upflow in a seismically active inhabited area. In H. S. Virk (Ed.), Rare gas geochemistry applications in earth \& environmental sciences (pp. 211-233). Amritsar: Guru Nanak Dev University.

3. Pfanz, H., Yüce, G., D'Andria, F., D'Alessandro, W., Pfanz, B., Manetas, Y., \& Papatheodorou, G. (2014). The ancient gates to hell and their relevance to geogenic $\mathrm{CO}_{2}$. In P. Wexler (Ed.), History of toxicology and environmental health (pp. 92-117). Oxford: Elsevier Press.

4. Ballagi, F. (1995). A szénsavgázfürdő jelentősége a perifériás érbetegek rehabilitációjában. Érbetegségek, 2(3), 21-27.

5. Szalainé, Cs. B., \& Dózsa, Cs. (2011). A mofetta kezelés - a kiaknázatlan nemzeti kincs. IME, 10(1), 45-49.

6. Czakó, T., \& Zelenka, T. (1981). New data about the neotectonics of Mátra Mountains, Northern Hungary.
Adv. Space Res., 1(10), 289-298. DOI: 10.1016/02731177(81)90406-3.

7. Tóth, E., Boros, D., Samuelsson, L., Deák, F., Marx, G., \& Sükösd, Cs. (1994). High radon activity in Northeast Hungary. Phys. Scr., 50(6), 726-730. DOI: 10.1088/0031-8949/50/6/020.

8. Csige, I., \& Csegzi, S. (2001). The Radamon radon detector and an example of application. Radiat. Meas., 34(1/6), 437-440. DOI: 10.1016/S13504487(01)00202-5.

9. Genrich, V. (1993). AlphaGUARD PQ2000/MC50. Multiparameter Radon Monitor. Characterisation of its physical properties under normal climatic and severe environmental conditions. User manual. Frankfurt, Germany: Genitron Instruments $\mathrm{GmbH}$.

10. Várhegyi, A., \& Hakl, J. (1994). A silicon sensor based radon monitoring device and its use in environmental geophysics. Geophys. Trans., 39(4), 289-302. 